\title{
Limiting Key Drilling Parameters to Avoid or Mitigate Mud Losses in the Hartha Formation, Rumaila Field, Iraq
}

Abo Taleb T. Al-Hameedi', Husam H. Alkinani', Shari Dunn-Norman ${ }^{1 *}$, Ralph E. Flori', Steven A. Hilgedick ${ }^{1}$ and Ahmed S. Amer ${ }^{2}$

${ }^{1}$ Missouri University of Science and Technology, Rolla, MO, USA

${ }^{2}$ Newpark Technology Center, Katy, TX, USA

\begin{abstract}
Wells drilled in Rumaila field are highly susceptible to lost circulation problems when drilling through the Hartha formation. This paper presents an extended statistical work and sensitivity analysis models of lost circulation events in more than 100 wells drilled in Rumaila field. Lost circulation data are extracted from daily drilling reports, final reports, and technical reports. The volume loss model is conducted to predict the mud losses in the Hartha formation. Observations that are made from the volume loss model are ECD, MW, and Yp have a significant impact on lost circulation respectively; however, SPM, RPM, and ROP have a minor effect on the mud losses. Equivalent circulation density model is obtained to estimate ECD in the Hartha zone, and from this model can be deduced that MW, ROP, and $Q$ have a significant impact on ECD respectively; nevertheless, RPM and Yp have a minor impact on the ECD. The rate of penetration model is made to estimate ROP in the Hatha zone. It is concluded that WOB, RPM, and SPM have a significant impact on the ROP respectively. Due to the lack of published studies for the Hartha formation, this work can serve as a practical resource for drilling through this formation.
\end{abstract}

Keywords: Drilling; Hartha formation; Rumaila field; Wellbore; Porosity

\begin{abstract}
Abbreviations: APL: Annular Pressure Loss; bbl/hr: barrels per hour; DDR: Daily Drilling Report; DOH: Diameter of Open Hole; ECD: Equivalent Circulation Density; FC: Float Collar; FS: Float Shoe; gm/cc: gram per cubed centimeter; in: Inch; L/min: Litter per minute; m: meter; $\mathrm{m}^{3} / \mathrm{hr}$ : cubed meter per hour; MW: Mud Weight; NPT: Non-productive Time; Q: Flow Rate; ROP: Rate of Penetration; RPM: Revolutions per Minute; SPM: Stroke per Minute; VIF: Variance Inflation Factor; WOB: Weight of Bit; WON: Without Nozzles; Yp: Yield of Point Viscosity
\end{abstract}

\section{Introduction}

Lost circulation is a common drilling problem in highly permeable formations, depleted reservoirs, and fractured or cavernous formations. Lost circulation problems may occur from shallow, unconsolidated formations to deeper, consolidated formations as a result of fracturing of the wellbore wall from high pressure applied by the drilling mud [1]. Lost circulation may be the reduction or absence of mud returns. The industry spends millions of dollars every year to combat lost circulation and its associated detrimental effects such as non-productive time (NPT) on the rig, stuck pipe, blow-outs, and less frequently, the abandonment of expensive wells.

This paper shows the application of develop a model for mud loss volumes within the Hartha formation in the Rumaila field in Iraq. The resulting model is compared to models developed for the Dammam and Shuaiba formations in the same field [2]. The study summarizes mud loss and lost circulation information extracted from drilling data from the Hartha formation and the lost circulation screening criteria developed for this formation, based on the historical mud loss and lost circulation problems. Three mathematical models have been created to stop or mitigate the problems, and potential solutions found by this study. The lithology of the Hartha formation is limestone. The properties of this limestone is mudstone, occasionally wackestone to grain stone, white, light gray to gray, occasionally pinkish gray, fine crystalline, no visible porosity, argillaceous, occasionally glauconitic, chalky in place no oil show.

Lost circulation events are categorized according to the total volume of fluid lost during the event. The volume of mud losses depends on number of factors, including formation properties, drilling fluid properties, and formation breakdown pressure. The categories of losses have been described as follows, depending on the volumes of mud losses and thief formation. The Hartha formation will be prone to all kinds of the drilling mud losses [3].

\section{Hartha Formation}

The Hartha formation is the second zone that is usually prone to lost circulation problems. Mud losses in the Hartha formation are more complicated than Dammam formation. This zone is deeper (formation top $11660 \mathrm{~m}$ ), and it is located below transitional zones like Tayarat and Ummer-Radhuma zones which have abnormal pressures and $\mathrm{H}_{2} \mathrm{~S}$ flow.

Figure 1 shows the borehole and well construction typical of a well drilled in the Rumaila field at the time the well passes through the Hartha formation. 13-3/8" casing has been set and most commonly a 12 $1 / 4$ " bit is used to drill through the formation. The Dammam formation has been drilled and is exposed open hole while the Hartha formation is drilled. A lost circulation event is shown near the bottom of the open hole in Figure 1, but it is possible to have losses simultaneously the Dammam and Hartha formations, or only losses in Hartha as it is drilled. Field methods used to drill Hartha are similar to those noted for Dammam, i.e., reduced WOB, RPM, SPM; adjusting mud properties; slow are careful removal or insertion of drill pipe to avoid surging, and breaking gel strength with rotation [4].

Corresponding author: Shari Dunn-Norman, Missouri University of Science and Technology, Rolla, MO, USA, Tel: +1-573 - 341- 4840; E-mail: caolila@mst.edu

Received September 25, 2017; Accepted October 26, 2017; Published October 31, 2017

Citation: Al-Hameedi AT, Alkinani HH, Dunn-Norman S, Flori RE, Hilgedick SA Amer AS (2017) Limiting Key Drilling Parameters to Avoid or Mitigate Mud Losses in the Hartha Formation, Rumaila Field, Iraq. J Pet Environ Biotechnol 8: 345. doi: 10.4172/2157-7463.1000345

Copyright: ( 2017 Al-Hameedi AT, et al. This is an open-access article distributed under the terms of the Creative Commons Attribution License, which permits unrestricted use, distribution, and reproduction in any medium, provided the original author and source are credited. 


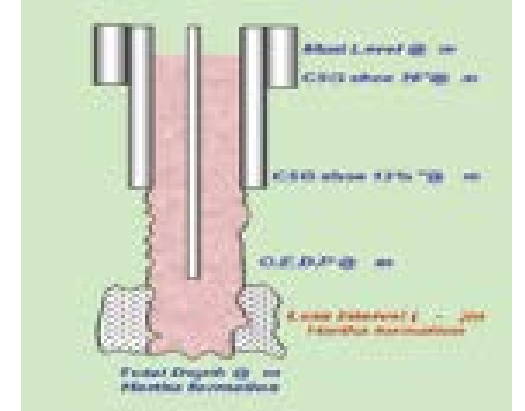

Figure 1: Lost circulation mud in the Hartha formation.

\section{Methodology}

Lost circulation events were identified for more than 100 wells discussed in this comprehensive statistical study, according to the formation and depth. Drilling parameters which are known to have the greatest impact and the lowest influence on lost circulation, and readily adjusted during the drilling operations were tabled for analyses. This section presents samples of the wells data, including the number of wells analyzed for the Hartha formation. These data have been analyzed to determine ranges for the key drilling parameters and mud properties that have the greatest chance of avoiding or mitigating lost circulation in this formation. Actually, all these real data precisely collected from various daily drilling report (DDR), final reports, and technical reports. A broad statistical work has been made to determine which drilling mud properties and operational drilling parameters that have a pivotal influence on lost circulation (Al-Hameedi et al., 2017). This extensive study shows that all mud weight (MW), equivalent circulation density (ECD), yield point (Yp) have a direct impact on lost circulation whereas SPM, RPM, ROP, WOB and bit nozzles directly or indirectly effect on this problem [3].

Statistical analysis was carried out to develop models for volume losses, which also requied development of models for ECD and ROP. The volume losses, ECD, and ROP are influenced by multiple parameters. Therefore, a simple linear regression model cannot be applied as it can only have one independent variable for one dependent variable [5]. For the previous reason, multi-regression models were established for the volume losses, ECD, and ROP. Multi-linear regression models allow multiple independent variables for one dependent variable [5]. All parameters are tested to determine the magnitude of the effect on the volume loss, ECD, and ROP models. A confidence level of $95 \%$ is used to test the significance of each parameter. Thus, any parameter with a p-value greater than $5 \%$ will be ignored in the model and vice versa. Sensitivity analysis was also conducted for the volume loss model, ECD model, and ROP model, to examine which parameter has the highest influence in each model and to test the effect of every parameter in all models [2].

This paper builds upon work in the Dammam formation to control on the mud losses in the Hartha formation [3]. Applying that methodology results in varied mathematical models due to the differences in input data. The construction of the mathematical correlation significantly relies on depth, lithology, drilling fluid properties, and operational drilling parameters. While the models are in the same form, the coefficients vary greatly from one formation to another.

\section{Volume Loss Model}

Multi-linear regression was performed for the volume loss as a function of MW, ECD, and Yp. Figures 2-4 show the leverage plots for MW, ECD, and Yp respectively. MW, ECD, and Yp are the significant parameters for the volume loss model. This suggests that it is possible to estimate the mud losses using the previous three parameters. ROP, SPM, and RPM were omitted as they showed little effect on volume loss. The volume loss model expressed by Eq. (1).

Mud Losses $=-1915.757+530.782 \times \mathrm{MW}(\mathrm{gm} / \mathrm{cc})+1144.376 \times$ $\mathrm{ECD}(\mathrm{gm} / \mathrm{cc})+0.582 \times \mathrm{Yp}\left(\mathrm{Ibf} / 100 \mathrm{ft}^{2}\right)($ Eq.1)

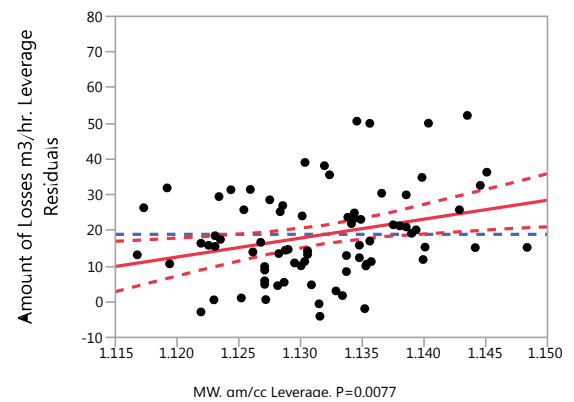

Figure 2: Leverage plot of MW for volume loss model.

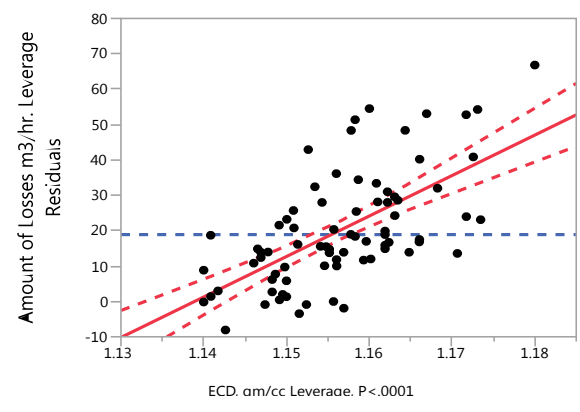

Figure 3: Leverage plot of ECD for volume loss model.

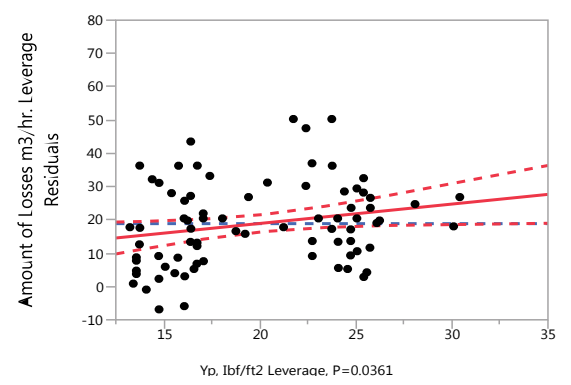

Figure 4: Leverage plot of Yp for volume loss model.

Figure 5 shows the actual versus the predicted mud losses. The $\mathrm{R}$-squared of this model is 0.719 ; however, the adjusted R-squared is 0.709 , which is a modified version of R-squared that accounts for the number of independent variables and should be used for the multi-liner regression [6].

Figure 6 shows the residual plot for the volume loss model. If the points in the residual plot are randomly distributed (no trend is shown), the linear regression model is valid; otherwise, a non-linear model should be used [6]. The points in the residual plot are randomly distributed, this confirms that a linear regression model is appropriate for the data. 


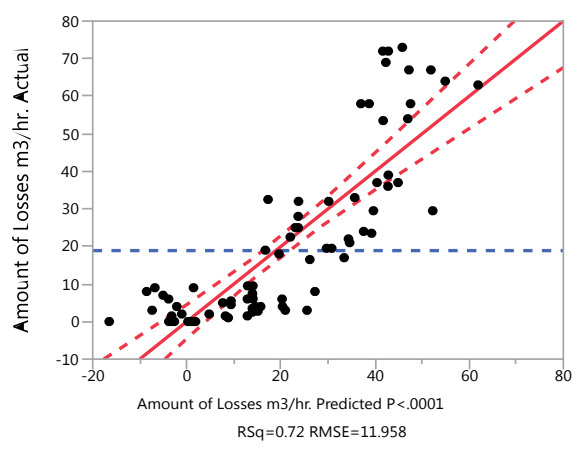

Figure 5: The actual versus the predicted mud losses.

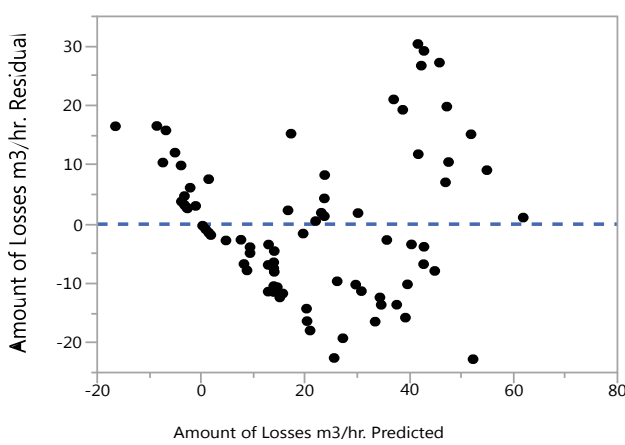

Figure 6: Residual plot for volume loss model.

Variance Inflation Factor (VIF) test is used to test for the multicollinearity phenomena in the volume loss model. Montgomery suggested that if VIF is greater than 5 or 10 , then the regression coefficients are poorly estimated due to multi-collinearity. Table 1 shows the summary of the p-values and VIF test. No VIF value exceeded 5, this can lead to the conclusion of no multicollinearity is observed in the model.

\begin{tabular}{|c|c|c|c|c|c|}
\hline Term & Estimate & Std Error & $\mathbf{t ~ R a t i o}$ & Prob $>|\mathbf{t}|$ & VIF Test \\
\hline Intercept & -1915.757 & 165.7669 & -11.56 & $<.0001$ &. \\
\hline MW, gm/cc & 530.7823 & 194.3577 & 2.73 & 0.0077 & 1.81323 \\
\hline ECD, gm/cc & 1144.376 & 141.6391 & 8.08 & $<.0001$ & 1.95161 \\
\hline Yp, Ibf/100ft ${ }^{2}$ & 0.582197 & 0.27322 & 2.13 & 0.0361 & 1.26712 \\
\hline
\end{tabular}

Table 1: Summary of p-values and VIF test.

The results of the sensitivity analysis that was conducted for the volume loss model showed that ECD is the most effective parameter in the model of volume loss then MW comes after. Also, the mud losses are least influenced by the Yp, but Yp is a significant parameter and it should be included in the model as it is proven by the statistical analysis.

\section{Equivalent Circulation Density (ECD) Model}

A multi-linear regression was performed to estimate the ECD based on MW, ROP, and flow rate $(\mathrm{Q})$, which were shown to have the largest influence on ECD. Figures 7, 8, and 9 show the leverage plots for MW, ROP, and Q respectively. A model for ECD was developed based on MW, ROP, and Q, prior drilling the Hartha formation, and is shown in Eq. (2).

$\mathrm{ECD}=0.9895+0.125 \times \mathrm{MW}(\mathrm{gm} / \mathrm{cc})+0.0068 \times \mathrm{ROP}(\mathrm{m} / \mathrm{hr})-$ $0.000009901 \times \mathrm{Q}(\mathrm{L} / \mathrm{min})$ Eq. (2).

The ECD calculated using Eq. (2) can be used as an input for Eq. (1) (volume loss model), since the actual ECD is a function of drilling parameters which may vary between drilling operations. Eq. (2) gives a good estimation for the ECD in Hartha formation. Figure 10 shows the actual versus the predicted ECD. The adjusted R-squared is 0.890 (Figure 10). Figure 11 shows residual plot for the ECD model. No trend is observed in the data; this suggests that the linear model is valid for this data.

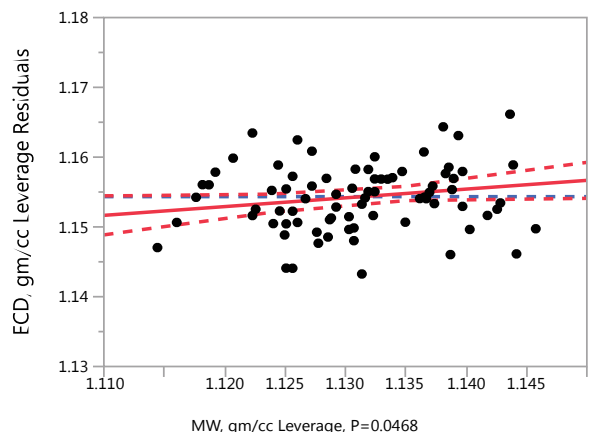

Figure 7: Leverage plot of MW for ECD model.

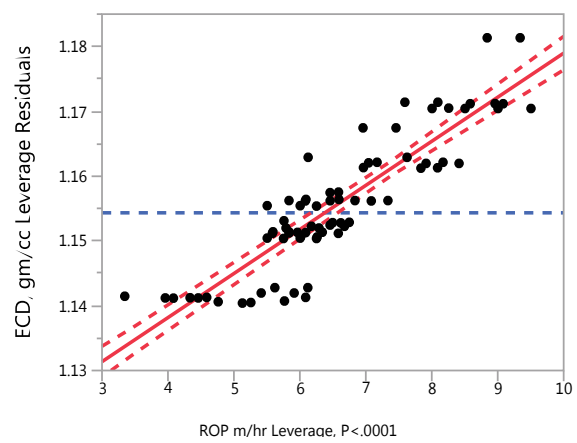

Figure 8: Leverage plot of ROP for ECD model.

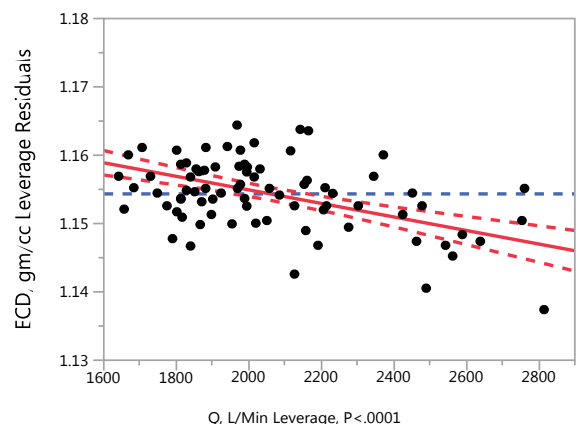

Figure 9: Leverage Plot of $Q$ for ECD model.

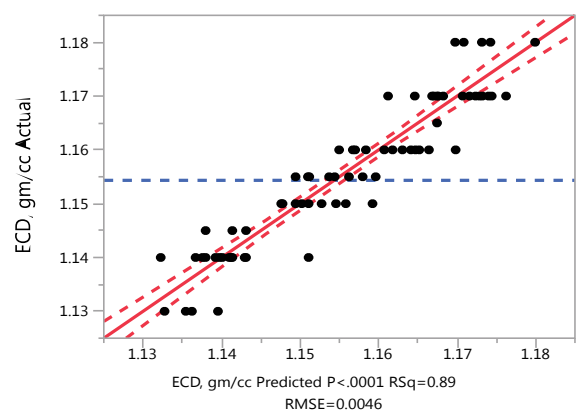

Figure 10: Actual versus predicted ECD. 
Table 2 shows the results of the VIF test and p-values. No VIF value exceeded 5 , this concludes that there is no multicollinearity in this model. The results of the sensitivity analysis that was conducted for the ECD model showed that the ECD is mostly influenced by MW, ROP, and $\mathrm{Q}$ respectively. As the MW and ROP increase, the ECD increases; however, as Q increases, the ECD decreases.

\begin{tabular}{|c|c|c|c|c|c|}
\hline Term & Estimate & Std Error & t Ratio & Prob $>|\mathbf{t}|$ & VIF Test \\
\hline Intercept & 0.98953 & 0.069583 & 14.22 & $<.0001$ &. \\
\hline ROP m/hr & 0.006802 & 0.000325 & 20.91 & $<.0001$ & 1.792130 \\
\hline MW, gm/cc & 0.125352 & 0.062208 & 2.02 & 0.0468 & 1.619561 \\
\hline Q, L/Min & -0.00001 & $1.67 e-6$ & -5.93 & $<.0001$ & 1.166721 \\
\hline
\end{tabular}

Table 2: Summary of VIF and p-values for the ECD model.

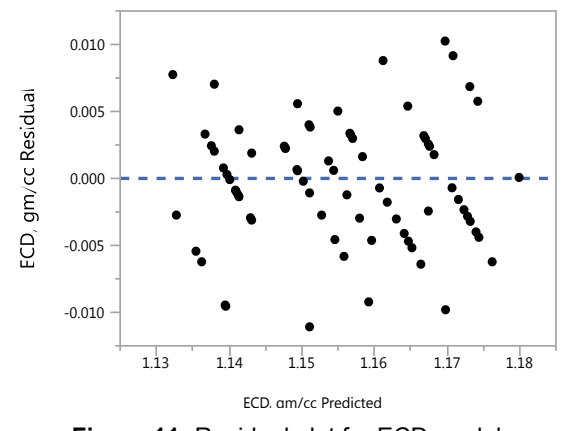

Figure 11: Residual plot for ECD model.

\section{Rate of Penetration (ROP) Model}

Because the ROP is affected by multiple parameters, a multi-linear regression was conducted to estimate the ROP in the Hartha formation. The drilling parameters which have significant effect on ROP are RPM, SPM, and WOB. Figures 12, 13, and 14 show the leverage plots for these parameters respectively.

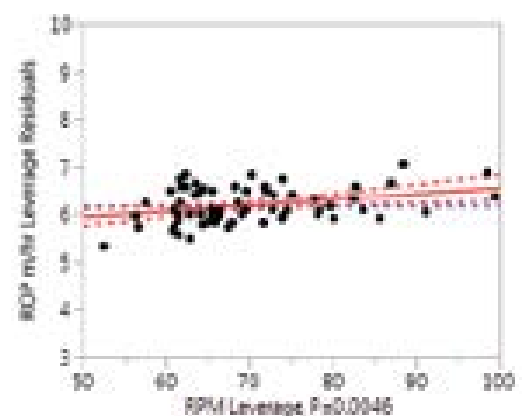

Figure 12: Leverage plot of RPM for ROP model.

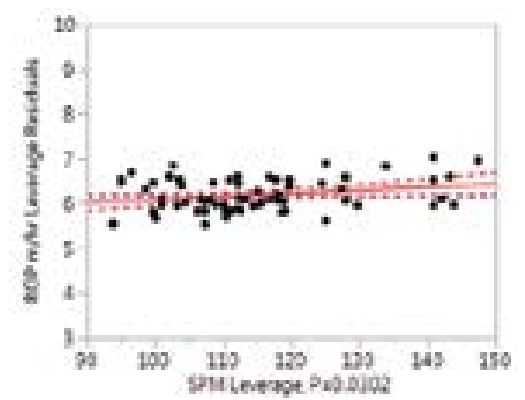

Figure 13: Leverage plot of SPM for ROP model.

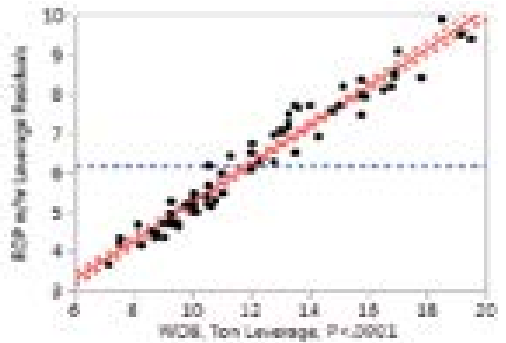

Figure 14: Leverage plot of WOB for ROP model.

Based on the influence of RPM, SPM, and WOB on ROP, the ROP model for the Hartha formation is expressed using Eq. (3).

$\mathrm{ROP}=-1.312+0.007 \times \mathrm{SPM}+0.0124 \times \mathrm{RPM}+0.489 \times \mathrm{WOB}(\mathrm{Eq} .3)$

Eq. (3) gives a good estimation for the ROP in the Hartha formation. In addition, the results of Eq. (3) can be used as an input for Eq. (2) (ECD model). Figure 15 shows the results of the actual versus the predicted ROP, with an adjusted R-squared of 0.967 . Figure 16 shows the results of the residual plot for the ROP model. The data are scattered, and no trend is observed. Thus, the linear model is valid for this data.

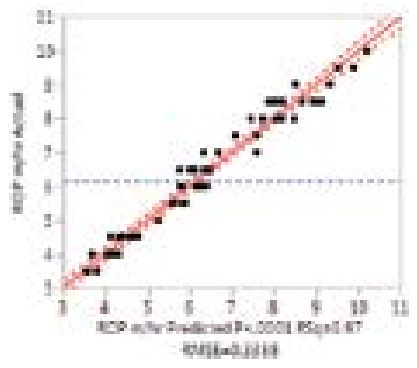

Figure 15: Actual versus predicted ROP.

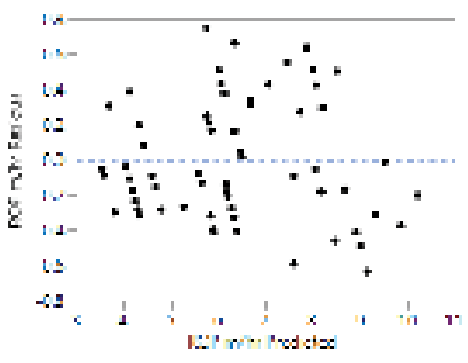

Figure 16: Residual plot for ROP.

Table 3 shows summary results for VIF and p-value. All VIF values are less than 5. Thus, no multicollinearity is noticed in this model. The results of the sensitivity analysis that was conducted for the ROP model showed that the ROP is highly influenced by WOB. This can conclude that the ROP can be highly improved by increasing the WOB. In addition, RPM affects the ROP more than SPM.

\begin{tabular}{|c|c|c|c|c|c|}
\hline Term & Estimate & Std Error & $\mathbf{t}$ Ratio & Prob $>|\mathbf{t}|$ & VIF Test \\
\hline Intercept & -1.311612 & 0.382355 & -3.43 & 0.0010 &. \\
\hline RPM & 0.012399 & 0.004236 & 2.93 & 0.0046 & 1.1984 \\
\hline SPM & 0.007012 & 0.003169 & 2.21 & 0.0302 & 1.1948 \\
\hline WOB, Ton & 0.488670 & 0.012637 & 38.67 & $<.0001$ & 1.2729 \\
\hline
\end{tabular}

Table 3: Summary of VIF and P-values for the ROP model. 


\section{Model Verification and Use}

The purpose of this work was to develop a more systematic approach to determining acceptable drilling parameters to mitigate mud losses in the Hartha formation. The models developed here combine to achieve this aim. The ROP can be predicted using equation 3, which is an input for equation 2 to estimate ECD. This ECD estimate is an input for the volume loss model, along with the estimated ROP and MW. These make it possible to estimate, before drilling operations in the Hartha formation, volume losses as a function of operational drilling parameters. Inversely this provides a tool to determine the operational drilling parameters for future operations by selecting an acceptable operational volume loss.

To examining the validity of these models, actual values for ROP, ECD, and resulting volume loss from field data were compared estimated values for each. Both partial and severe mud losses have been examined to assess validity across a large range of volume losses. Field data also included two types of the drilling fluid used in previous wells within the Hartha formation. Tables 4 and 5 show the mud loss event counts for original wells used to develop the models and wells used for testing model results for two types of mud (FCL mud and polymer mud), respectively. Figures 17-22 are plots of predicted values of ROP, ECD and the mud loss plotted against actual data (FCL mud and polymer mud), respectively for partial losses. There is strong agreement in results for ROP, ECD, and the volume loss models.

\begin{tabular}{|c|c|c|c|c|c|}
\hline $\begin{array}{c}\text { Type of the } \\
\text { Losses }\end{array}$ & New Wells & $\begin{array}{c}\text { Original } \\
\text { Wells }\end{array}$ & $\begin{array}{c}\text { Total New } \\
\text { Wells }\end{array}$ & $\begin{array}{c}\text { Total Old } \\
\text { Wells }\end{array}$ & $\begin{array}{c}\text { Total } \\
\text { Wells }\end{array}$ \\
\hline Partial Losses & 22 & 6 & 60 & 17 & 77 \\
\hline $\begin{array}{c}\text { Severe } \\
\text { Losses }\end{array}$ & 38 & 11 & 60 & & \\
\hline
\end{tabular}

Table 4: Summary of the application of the real field data (FCL Drilling Mud).

\begin{tabular}{|c|c|c|c|c|c|}
\hline $\begin{array}{c}\text { Type of the } \\
\text { Losses }\end{array}$ & New Wells & $\begin{array}{c}\text { Original } \\
\text { Wells }\end{array}$ & $\begin{array}{c}\text { Total New } \\
\text { Wells }\end{array}$ & $\begin{array}{c}\text { Total Old } \\
\text { Wells }\end{array}$ & $\begin{array}{c}\text { Total } \\
\text { Wells }\end{array}$ \\
\hline Partial Losses & 27 & 10 & 66 & 23 & 89 \\
\hline $\begin{array}{c}\text { Severe } \\
\text { Losses }\end{array}$ & 39 & 13 & 66 & 23 & \\
\hline
\end{tabular}

Table 5: Summary of the application of the real field data (Polymer Drilling Mud).

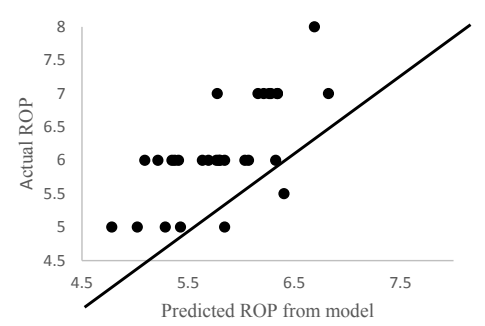

Figure 17: Actual vs. predicted ROP for partial losses (FCL mud).

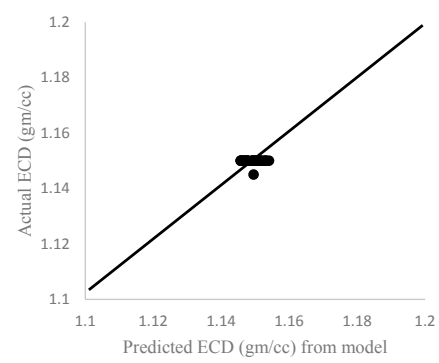

Figure 18: Actual vs. predicted ECD for partial losses (FCL mud).

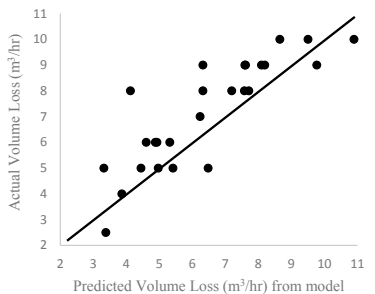

Figure 19: Actual vs. predicted volume loss for partial losses (FCL mud)

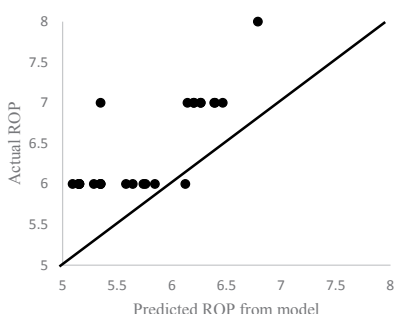

Figure 20: Actual vs. predicted ROP for partial losses (polymer mud)

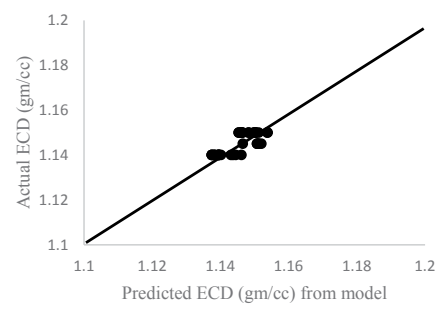

Figure 21: Actual vs. predicted ECD for partial losses (polymer mud).

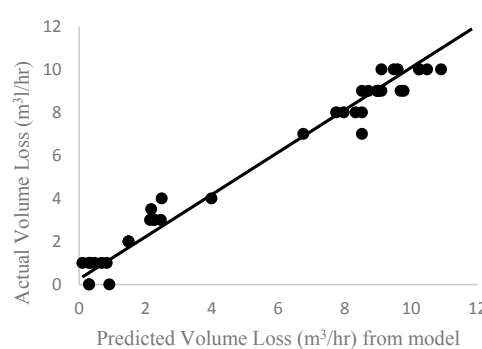

Figure 22: Actual vs. predicted volume loss for partial losses (polymer mud).

Figures 23-28 are plots of predicted values of ROP, ECD and the mud losses against actual data (FCL mud and polymer mud), respectively for severe losses. There is variation agreement in results for ROP and ECD. However, the net result shows a strong correlation between predicted and actual volume losses for severe mud loss events.

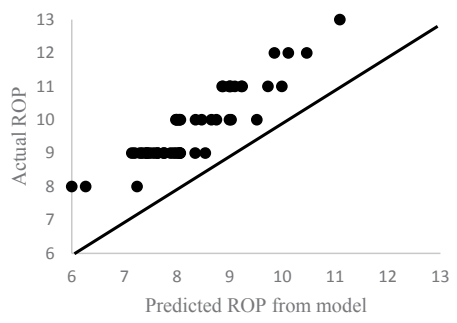

Figure 23: Actual vs. predicted ROP for severe losses (FCL mud). 


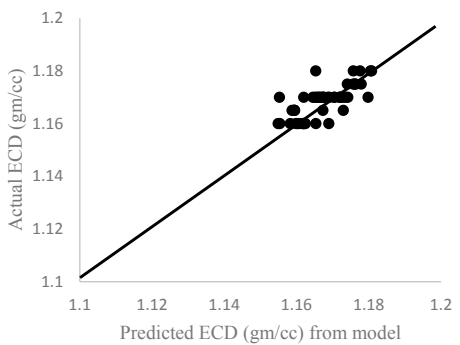

Figure 24: Actual vs. predicted ECD for severe losses (FCL mud).

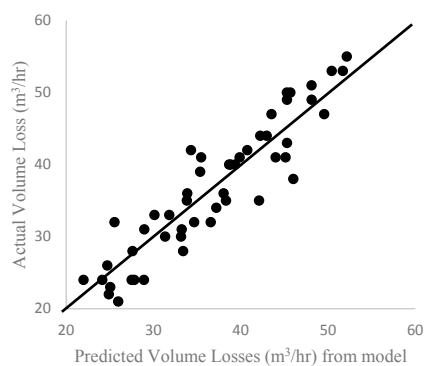

Figure 25: Actual vs. predicted volume loss for severe losses (FCL mud)

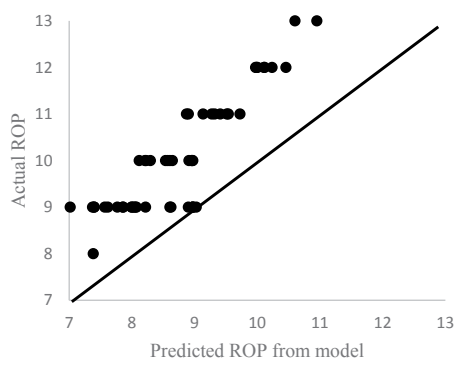

Figure 26: Actual vs. predicted ROP for severe losses (polymer mud).

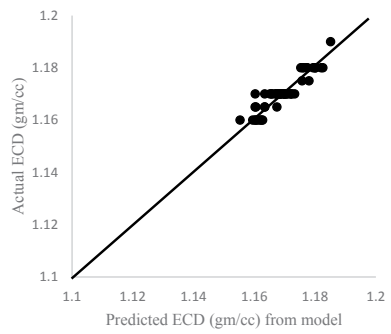

Figure 27: Actual vs. predicted ECD for severe losses (polymer mud).

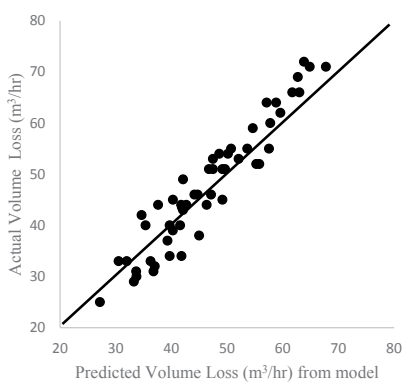

Figure 28: Actual vs. predicted volume loss for severe losses (polymer mud).

\section{Comparison of Formation Specific Models}

The methodology applied to the models developed for the Hartha formation have also been applied to two other limestone formations, the Dammam and Shuaiba [3], which also pose great risk for lost circulation during drilling operations. Table 6 shows the average MW and depth for each formation as well as the first, second, and third coefficients $(\mathrm{C} 1, \mathrm{C} 2$, and C3) for the formation's corresponding volume loss model.

\begin{tabular}{|c|c|c|c|c|c|}
\hline Term & Estimate & Std Error & t Ratio & Prob>|t| & VIF Test \\
\hline Intercept & -1.311612 & 0.382355 & -3.43 & 0.0010 &. \\
\hline RPM & 0.012399 & 0.004236 & 2.93 & 0.0046 & 1.1984 \\
\hline SPM & 0.007012 & 0.003169 & 2.21 & 0.0302 & 1.1948 \\
\hline WOB, Ton & 0.488670 & 0.012637 & 38.67 & $<.0001$ & 1.2729 \\
\hline
\end{tabular}

Figures 29-31 show C1, C2, and C3 for each formation plotted as a function of Depth. Figures 32-34 and 34 show C1, C2, and C3 values for each formation plotted as a function of MW. A simple linear trend has been included for all figures. These plots show commonality between coefficient variation as a function of depth and MW. This commonality, combined with general trends of the individual coefficients suggest the possibility of estimation of the coefficients determined through this methodology without the use of such an extensive data set $[7,8]$.

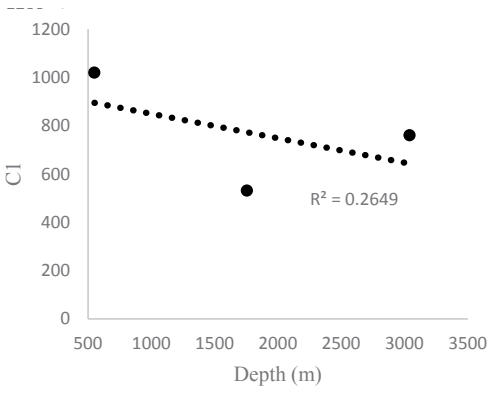

Figure 29: Coefficient 1 versus depth.

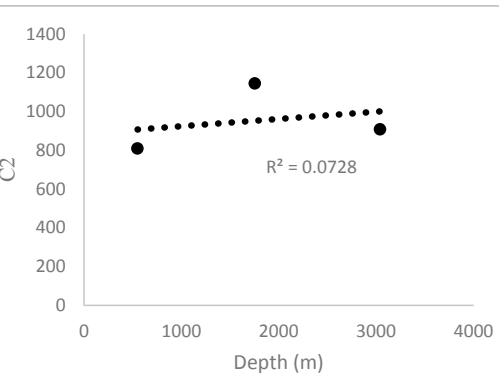

Figure 30: Coefficient 2 versus depth

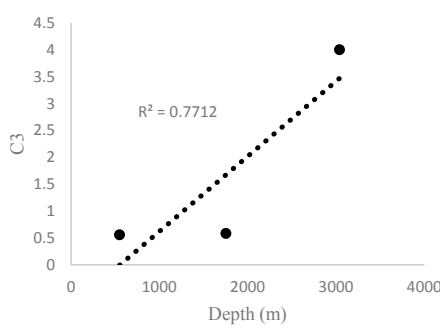

Figure 31: Coefficient 3 versus depth. 
Citation: Al-Hameedi AT, Alkinani HH, Dunn-Norman S, Flori RE, Hilgedick SA, Amer AS (2017) Limiting Key Drilling Parameters to Avoid or Mitigate Mud Losses in the Hartha Formation, Rumaila Field, Iraq. J Pet Environ Biotechnol 8: 345. doi: 10.4172/2157-7463.1000345

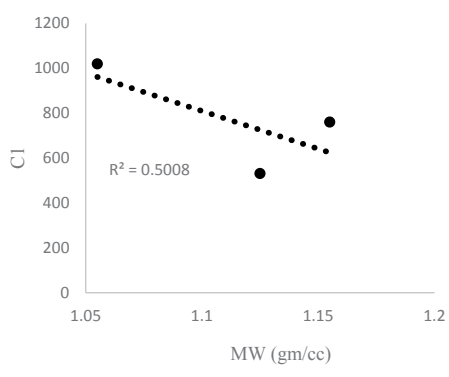

Figure 32: Coefficient 1 versus MW

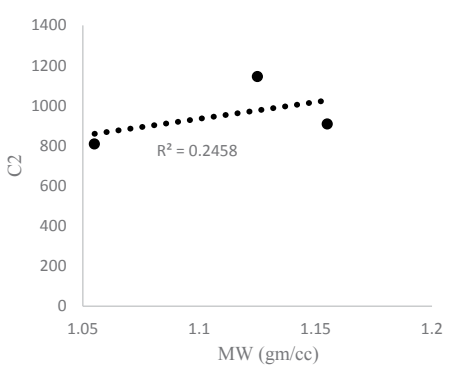

Figure 33: Coefficient 2 versus MW.

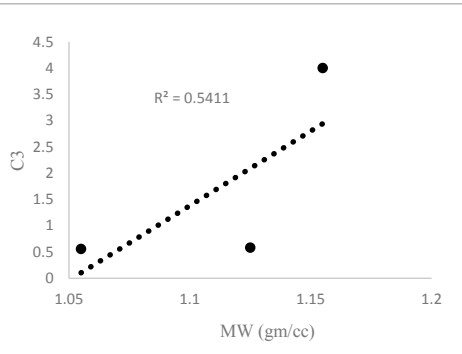

Figure 34: Coefficient 3 versus MW.

\section{Conclusion}

This paper presents a comprehensive statistical study of more than 100 wells in the Rumaila field. This work includes the application of multilinear analysis to develop mathematical models to estimate volume losses, as well as the ECD and ROP associated with those losses. The resulting models vary from those previously developed through this methodology as shown by a comparison of three models developed for different formations. Based on this study, the following conclusions are made:

1. Based on reviewing drilling reports, it is possible to extract lost circulation event data and determine operational parameters and drilling mud parameters that can mitigate or aggravate mud losses while drilling through the Hartha formation.

2. The volume loss model, which was developed, is capable of predicting lost circulation events and volumes in the Hartha formation.

3. ECD, MW, and Yp have a much greater effect on the volume of mud losses than SPM, RPM, and ROP.
4. The ECD model was developed to estimate ECD within the Hartha formation without knowledge of all operational drilling parameters. This model can then be used to estimate the ECD, which is required as in input to the volume loss model.

5. The ROP developed here may be used to estimate the ROP within the Hartha formation without knowledge of all operational drilling parameters. This model is required to estimate the ROP prior to drilling, to be used and in input to the ECD and subsequent volume loss model.

6. The parameters impacting volume loss, ECD, and ROP were examined to determine those which impact each the greatest. Those parameters were the basis for each model, and the Variance Inflation Factor (VIF) test was used to test for the multicollinearity phenomena in each model to maximize the accuracy, and improve each mathematical model.

7. One challenge in drilling wells in the Rumaila field is the inconsistency of approaches to the lost circulation problem. Hence, a formalized methodology for responding to losses in the Rumaila field provides a means of assisting drilling personnel in the mitigation of mud losses in a systematic way.

8. Comparison of three volume loss, ECD, and ROP models shows strong trends for the coefficients in these models with respect to depth. This suggests the possibility of combining field data and models from multiple formations to develop a non-formation specific model for volume losses.

\section{Acknowledgments}

The authors would like to thank South Oil Company from Iraq and British Petroleum Company for providing us various real field data.

\section{References}

1. Moore PL (1986) Drilling Practices Manual. (2nd edn), Penn Well Publishing Company. Tulsa, Oklahoma, USA.

2. Al-Hameedi AT, Dunn-Norman S, Alkinani HH, Flori RE, Hilgedick SA (2017) Limiting drilling parameters to control mud losses in the Dammam Formation, Rumaila Field, Iraq. Paper ARMA 17-0930 published, and it was presented at the $51^{\text {st }}$ US Rock Mechanics/Geomechanics Symposium held in San Francisco, California, USA.

3. Al-Hameedi AT, Dunn-Norman S, Alkinani HH, Flori RE, Hilgedick SA (2017) Limiting drilling parameters to control mud losses in the Shuaiba formation, Rumaila field, Iraq. Paper AADE-17- NTCE- 45 published, and it was presented at the 2017 AADE National Technical Conference and Exhibition held at the Hilton Houston North Hotel, Houston, Texas, USA.

4. South oil Company (2007) Various Daily Reports, Final Reports, and Tests for 2007, 2008, 2009 and 2010. Several Drilled Wells, Southern Ramiala Field, Basra, Iraq.

5. Sanford W (2005) Applied Linear Regression (3rd edn). Wiley, New Jersey, USA.

6. Montgomery DC, Peck EA, Vining GG (2001) Introduction to linear regression analysis. (3rd edn), Wiley, New York, USA

7. Nayberg TM, Petty BR (1987) Laboratory study of lost circulation materials for use in oil-base drilling muds. Paper SPE 14995 presented at the Deep Drilling and Production Symposium of the Society of Petroleum Engineers Held in Amarillo, TX, USA.

8. British Petroleum Company (2013) Various Daily Reports, Final Reports, and Tests for 2013, 2014 and 2015. Several Drilled Wells, Southern Ramiala Field Basra, Iraq. 